\title{
Long-term Outcomes of Liver Transplant Patients with Human IMMUNODEFICIENCY VIRUS INFECTION AND END-STAGE-LIVER-DISEASE: SingLE CENTER EXPERIENCE
}

\author{
S. Vernadakis ${ }^{1}$, G. C. Sotiropoulos ${ }^{1}$, E. I. Brokalaki², S. Esser ${ }^{2}$, G. M. Kaiser ${ }^{1}$, V. R. Cicinnati ${ }^{3}$, \\ S. Beckebaum ${ }^{1}$, A. Paul ${ }^{1}$, Z. Mathé \\ ${ }^{1}$ Department of General, Visceral and Transplantation Surgery, ${ }^{2}$ Department of Dermatology, Vencrology and Allergology, \\ ${ }^{3}$ Department of Gastroenterology and Hepatology, University Hospital Essen, Essen, Germany
}

\begin{abstract}
Objective: Orthotopic-liver-transplantation (OLT) in patients with Human-Immunodeficiency-Virus infection (HIV) and end-stage-liver-disease (ESDL) is rarely reported. The purpose of this study is to describe our institutional experience on OLT for HIV positive patients.

Material and Methods: This is a retrospective study of all HIV-infected patients who underwent OLT at the University Hospital of Essen, from January 1996 to December 2009. Age, sex, HIV transmission-way, CDC-stage, etiology of ESDL, concomitant liver disease, last CD4cell count and HIV-viral load prior to OLT were collected and analysed. Standard calcineurin-inhibitors-based immunosuppression was applied. All patients received anti-fungal and anti-pneumocystis carinii pneumonia prophylaxis post-OLT. Results: Eight transplanted HIV-infected patients with a median age of 46 years (range 35-61years) were included. OLT indications were HCV $(\mathrm{n}=5), \mathrm{HBV}(\mathrm{n}=$ 2), HCV/HBV/HDV-related cirrhosis $(n=1)$ and acute liver-failure $(\mathrm{n}=1)$. At OLT, CD4 céll-counts ranged from 113-621 cells $/ \mu$, and HIV viral-loads from $<50-175,000$ copies $/ \mathrm{ml}$. Seven of eight patients were exposed to HAART before OLT. Patients were followed-up between 1-145 months. Five died 1, 3, 10, 31 and 34 months after OLT due to sepsis and graftfailure respectively. Graft-failure causes were recurrent hepatic-artery thrombosis, HCV-associated hepatitis and chemotherapy-induced liver damage due to Hodgkin-disease. One survivor is relisted for OLT due to recurrent chronic HCV-disease but non-progredient HIV-infection 145 months post-OLT. Two other survivors show stable liver function and non-progredient HIV-disease under HAART 21 and 58 months postOLT.

Conclusions: OLT in HIV-infected patients and ESLD is an acceptable therapeutic option in selected patients. Long-term survival can be achieved without HIV disease-progression under antiretroviral therapy and management of the viral hepatitis co-infection.
\end{abstract}

Key words: Human immunodeficiency virus; HIV infection; hepatocellular carcinoma; liver transplantation; liver cirrhosis; highly active antiretroviral therapy; HAART; hepatitis $\mathrm{C}$; HCV infection

\section{Abbreviations}

AIDS acquired immune deficiency syndrome

ALG anti-lymphocyte globulin

ATG anti-thymocyte globulin

CSA Cyclosporine A

ESLD end-stage-liver-disease

HAART highly active antiretroviral therapy

HBV hepatitis B virus

HCC hepatocellular carcinoma

$\mathrm{HCV}$ hepatitis $\mathrm{C}$ virus

HIV human immunodeficiency virus

MELD Model for end-stage liver disease-score

OLT orthotopic liver transplantation

OKT3 anti-CD3 monoclonal antibody

PI protease inhibitor

\section{INTRODUCTION}

Orthotopic liver transplantation (OLT) is the best therapeutic option for end-stage liver disease (ESDL), although it is limited by graft shortage and the need for appropriate patient selection [1-4]. Presence of Human Immunodeficiency Virus infection (HIV) used to be viewed as contraindication to transplantation for several reasons: a) the use of limited supply of donor organs with unknown long-term outcomes, b) effects of immunosuppression on the progression of HIV disease in already immunocompromised patients, c) risk of transmission of HIV to the medical and surgical staff, d) the timing for OLT, e) the risk of HBV and HCV recurrence post transplant [5-6].

In the past 15 years advances in highly active antiretroviral therapy (HAART), and the effective management and prophylaxis of opportunistic infections have changed the outcome of HIV-related disease, decreasing markedly the acquired immune deficiency syndrom (AIDS) mortality and developing HIV-disease to a chronic condition [7]. ESLD is increasingly recognized as a significant cause of morbidity and mortality among HIV-infected patients due to liver-related complications of co-infection with Hepatitis B(HBV) and Hepatitis C-Virus (HCV). $10 \%$ and $30 \%$ of HIV infected patients are co-infected with HBV and $\mathrm{HCV}$, respectively. Therefore, HIV-positive individuals are at greater risk of dying from complications of ESLD, rather than HIV complications [4]. 
We retrospectively analyzed a group of HIV-infected patients from the University Hospital Essen Transplant center with ESDL that underwent an OLT. The purpose of our analysis is to describe the long-term outcomes and the management strategies of HIV positive patients with ESDI, who undergo OLT.

\section{PATIENTS AND METHODS}

This retrospective analysis includes all HIV-infected patients with ESLD who underwent OLT at the University Hospital of Essen, from January 1996 to December 2009. The same standard criteria for listing a non-HIV ESDL-patient were used, in order for a HIV-infected patient to be waitlisted for OLT. Additional required criteria were a CD4 cell count $>100$ cells $/ \mu \mathrm{l}$ and a serum HIV-viral load in undetectable levels $<50$ copies $/ \mathrm{ml}$. Placement on the waiting list was decided after discussion by our multidisciplinary team, which included infections disease specialists, hepatologists, transplant surgeons, anesthesiologists and psychologists.

Demographic and clinical data were collected retrospectively for the HIV-cohort included: age, sex, HIV transmission- way, CDC-stadium, etiology of the liver disease, concomitant liver disease, MELD-Score, last CD4cell-count and HIV-viral load prior to OLT.

Concerning the OLT-surgical procedure used, six patients received a whole graft from a deceased donor, one received an extended right lobe split graft and one further patient a right lobe graft as a living donation from his wife.

Immunosuppression consisted of tacrolimus-based dual therapy with tapering corticosteroids over a 3month period. Tacrolimus doses were adjusted to achieve a target trough level of $12-15 \mathrm{ng} / \mathrm{ml}$ during the first week post-OLT, $10-12 \mathrm{ng} / \mathrm{ml}$ during the first 3 months posttransplant, $8-10 \mathrm{ng} / \mathrm{ml}$ thereafter during months 4-6, 6-8ng/ml during months 7-12 and approximately $5 \mathrm{ng} / \mathrm{ml}$ thereafter.

Cyclosporine A (CSA) based immunosuppression plus prednisone for induction was also used. CSA was dosed according to target levels $(150-200 \mathrm{ng} / \mathrm{ml}$ for weeks $0-2,100-150 \mathrm{ng} / \mathrm{ml}$ for weeks 3-11, 75-125 $\mathrm{ng} / \mathrm{ml}$ for week 12 and thereafter). OKT3, ALG, and ATG were not used for these patients.
Episodes of rejection were documented and confirmed by histopathology. A steroid cycle of an intravenously bolus of methylprednisolon $500 \mathrm{mg} / \mathrm{d}$ for 3 days was used in case of rejection. Any additional immunosuppressiv treatment or changes over time were noted.

All patients receiving HAART had their therapy recorded before and after OLT. All changes of the HAART therapy after OLT were documented.

The HBV-recurrence prevention protocol consisted of HBs-hyperimmunoglobulin administration of $10.000 \mathrm{IU}$ i.v starting during the anhepatic phase of OLT, followed by $10.0001 \mathrm{U}$ i.v once pro day for 1 week and maintenance therapy by monthly intramuscular infusions in order to keep serum levels of anti$\mathrm{HBs}>100 \mathrm{IU} / \mathrm{ml}$. All patients transplanted for $\mathrm{HBV}$ infection received dual immunoprophylaxis with additional lamivudine administration $300 \mathrm{mg} / \mathrm{d}$.

Patients with preexisting HCV infection were treated with pegylated interferon and ribavirin combination therapy post transplant, as soon as stable immunosuppression after initiation of HAART was established.

All patients received anti-fungal prophylaxis and anti-pneumocystis carinii pneumonia prophylaxis with trimethoprim - sulphamethoxasazole after OLT. Anticytomegalovirus and herpes simplex virus prophylaxis was also administered with ganciclovir, acyclovir and/or cytomegalovirus immune globulin.

The median, range and mean were used for the descriptive statistics. Patient survival was calculated using the Kaplan-Meier method and compared with the log rank test.

'The study was conducted according the declaration of Helsinki and its subsequent revisions and in agreement to good clinical practice guidelines.

\section{RESULTS}

A total of $8 \mathrm{HIV}$-infected patients $(6$ males and $2 \mathrm{fe}$ males) underwent OLT at our center during the study period. All OLTs were first transplants. The baseline characteristics of the 8 patients are shown in Table 1 . The majority of patients were male $(n=6)$ and the median age at transplantation was 46 years (range, 3561).

Among the $8 \mathrm{HIV}$ infected patients, two were also infected with $\mathrm{HBV}$ alone, one with chronic HCV

Table 1. Demographic details of HIV-infected patients and actiology of liver disease.

\begin{tabular}{|c|c|c|c|c|c|c|c|}
\hline ID & Age(ys) & Gender & $\begin{array}{l}\text { Transmission } \\
\text { risk factor }\end{array}$ & $\begin{array}{l}\text { CDC } \\
\text { Stage }\end{array}$ & Liver Disease & $\begin{array}{l}\text { MELD } \\
\text { Score }\end{array}$ & $\begin{array}{c}\text { Duration of HIV } \\
\text { diagnosis before } \\
\text { OLT(ys) }\end{array}$ \\
\hline 1 & 43 & $\mathrm{~F}$ & sexual & A2 & $\mathrm{ALV} / \mathrm{HBV}$ & 27 & 0 (at OLT) \\
\hline 2 & 44 & M & transfusion & A2 & $\mathrm{HBV} / \mathrm{HCV} / \mathrm{Hem}$ & 22 & 12 \\
\hline 3 & 58 & M & sexual & B3 & HBV & 15 & 13 \\
\hline 4 & 46 & M & transfusion & $\Lambda 2$ & $\mathrm{HBV} / \mathrm{HCV} / \mathrm{Hem}$ & 23 & 16 \\
\hline 5 & 48 & M & transfusion/ i.v drugs & B2 & $\mathrm{HBV} / \mathrm{HCV} / \mathrm{Hem}$ & 24 & 16 \\
\hline 6 & 48 & $\mathrm{~F}$ & i.v drugs & B3 & $\mathrm{HBV} / \mathrm{HCV} / \mathrm{HDV}$ & 25 & 17 \\
\hline 7 & 35 & M & transfusion & B3 & $\mathrm{HBV} / \mathrm{HCV}$ & 13 & 20 \\
\hline 8 & 61 & M & transfusion & $\mathrm{B} 2$ & $\mathrm{HCV} / \mathrm{HCC}$ & 13 & 21 \\
\hline
\end{tabular}


Table 2. CD4 counts, HIV-viral loads and HAART pre-OLT.

\begin{tabular}{lccc}
\hline ID & CD4 counts & Viral load & HAART \\
\hline 1 & 219 counts $/ \mu \mathrm{l}$ & 1450 copies $/ \mathrm{ml}$ & No \\
2 & 403 counts $/ \mu \mathrm{l}$ & $<250$ copies $/ \mathrm{ml}$ & Lamivudine, Zidovudine, Saquinavir \\
3 & 200 counts $/ \mu \mathrm{l}$ & $<50 \mathrm{copies} / \mathrm{ml}$ & Lamivudine, Stavudine, Efavirenz \\
4 & 233 counts $/ \mu \mathrm{l}$ & $<50 \mathrm{copies} / \mathrm{ml}$ & Lamivudine, Efavirenz, Stavudine \\
5 & $210 \mathrm{counts} / \mu \mathrm{l}$ & $<50 \mathrm{copies} / \mathrm{ml}$ & Lamivudine, Ritonavir, Stavudine \\
6 & 621 counts $/ \mu \mathrm{l}$ & $175000 \mathrm{copies} / \mathrm{ml}$ & Lamivudine, Stavudine, Nelfinavir \\
7 & 113 counts $/ \mu \mathrm{l}$ & $<50 \mathrm{copies} / \mathrm{ml}$ & Fosamprenavir, Ritonavir, Tenofovir, Emtricitabin \\
8 & 323 counts $/ \mu \mathrm{l}$ & $<50$ copies $/ \mathrm{ml}$ & Lamivudine, Lopinavir, Ritonavir, Stavudine \\
\hline
\end{tabular}

alone, and five with both HBV and HCV. One patient suffered from ESLD with HCV, HBV and hepatitis D virus infection. One patient had fulminant hepatic failure due to paracetamol intoxication secondary to chronic HBV. In addition in one HIV-positive patient with HCV an incidental multifocal HCC has been found in his liver explant.

One patient suffered from hemophilia B (patient 2) and two further from hemophilia A (patients 4, 5). All three of them and also patients 5,7 , and 8 had been infected with HIV and HCV by contaminated blood products. Two of the patients had a positive history of drug abuse; one of the patients had been infected by heterosexual contacts (patient 1) and one patient by homosexual contacts (patient 3).

The median CD4 cells-count was 226 cells $/ \mu \mathrm{l}$ (range: 113-621). Five of the HIV infected patients had an undetectable HIV viral load before OLT. Two had very low viral counts, and one had a viral load of 175,000 copies/ml (Table 2). All but one patient were receiving HAART therapy prior to OLT. The single patient not receiving HAART therapy had presented with fulminant hepatic failure secondary to paracetamol intoxication and was not known to have HIV prior to his presentation. The HAART regimens are shown in Table 2. The HAART regimens were adjusted by the infectious disease team depending on tolerability and genotypic sensitivity of the HIV.

Immunosuppression consisted of tacrolimus-based dual therapy with tapering corticosteroids over a 3month period in 4 patients (patient 1, 2, 7, 8). Cyclosporine A (CSA) based immunosuppression plus prednisone for induction was used for the other $4 \mathrm{pa}$ tients (patient 3, 4, 5, 6).

\section{SURVIVAL ANALYSIS}

The median follow up for the HIV-population was 26 months (range: 1 to 145 months). The actuarial 1-, 3-, and 5-year survival rate posttransplant were $63 \%, 31 \%$ and $31 \%$ respectively (Fig. 1 .).

The observed mortality from any cause was $62.5 \%$ (5 of 8 ). The causes of mortality in the five HIV infected patients are shown in the Table 3. Three of the five deaths $(60 \%)$, all occurring within 10 months after OLT, were due to severe septic conditions with progredient multiorgan failure.

Patients 2, 7 and 8 are alive 145, 58 and 21 months post-OLT, respectively. Patient 2 has been relisted for liver transplantation due to progressive HCV-associated cholestatic hepatitis with secondary graft failure.

\section{REJECTION AND IMMUNOSUPPRESSION}

Two of the $8 \mathrm{HIV}$ infected patients had acute allograft rejection as shown in Table 2, within one week to 4 months after OLT, which was successfully treated with high-dose steroid cycle and/or increase of tacrolimus

Table 3. Outcomes / morbitity and mortality data, following OL'T.

\begin{tabular}{|c|c|c|c|c|c|c|c|}
\hline ID & $\begin{array}{l}\text { Donor } \\
\text { age (ys) }\end{array}$ & Art of OLT & $\begin{array}{l}\text { Rejection } \\
\text { (yes/no) }\end{array}$ & $\begin{array}{l}\text { Immuno- } \\
\text { suppresion }\end{array}$ & $\begin{array}{l}\text { Early postop. } \\
\text { complications }\end{array}$ & $\begin{array}{l}\text { Survival } \\
\text { post-OLT } \\
\text { (months) }\end{array}$ & Cause of death \\
\hline 1 & 46 & whole graft & No & FK & CMV & 34 & $\begin{array}{l}\text { graft failure after } \\
\text { HBV-recurrence }\end{array}$ \\
\hline 2 & 63 & whole graft & Yes & $\mathrm{FK} / \mathrm{CSA}$ & Cholangitis, psychosis & 145 & alive \\
\hline 3 & 27 & whole graft & No & CSA, MMF & hep. artery thrombosis, CMV & 3 & Sepsis, MOF \\
\hline 4 & 15 & whole graft & No & CSA & CMV & 31 & Sepsis, MOF \\
\hline 5 & 40 & RLDLT & No & $\mathrm{CSA}$ & biliary leakage & 1 & Sepsis, MOF \\
\hline 6 & 16 & whole graft & No & CSA, MMF & & 10 & $\begin{array}{l}\text { graft failure, } \\
\text { GI-bleeding }\end{array}$ \\
\hline 7 & 37 & ext. right split & Yes & FK & $\begin{array}{l}\text { Critical illness } \\
\text { polyneuropathy }\end{array}$ & 58 & alive \\
\hline 8 & 66 & whole graft & No & FK & & 21 & alive \\
\hline
\end{tabular}




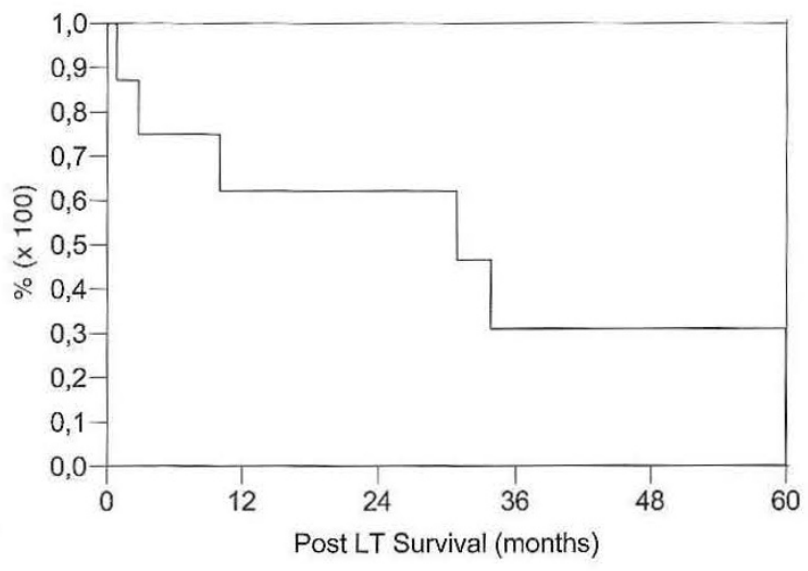

Fig. 1. Kaplan-Meier patient survival analysis of HIV-infected patients following OLT.

dose. OKT3, ALG, and ATG were not used for these patients. None of the patients experienced chronic rejection.

Four patients received immunosuppression with steroids and tacrolimus. Tacrolimus was changed to CSA in a single patient due to neurological manifestations (patient 2). The other four patients received immunosuppression with CSA and prednisone for induction after OLT. Two patients with renal insufficiency were subsequently treated additionally with mycophenolat mofetil (MMF) and reduced CSA doses to prevent further progression of renal insufficiency due to calcineurin-inhibitor-associated nephrotoxicity.

\section{HAART AND HIV-COURSE IN THE POST"IRANSPLANT SETIING}

HAART therapy was continued posttransplant in all HIV infected paticnts. In the single patient who had not received HAART before OLT, it was initiated after the OLT. In all patients low to undetectable HIV load levels were maintained post-OLT. Immune reconstitution under HAAR'T was observed in all patients with increase of the CD4 cells.

Patient 4 showed a stable CD4 T-cell count and undetectable HIV load during the first 20 months postOLT. When HAART was interrupted due to progression of the liver failure, secondary to chemotherapy against Hodgkin's disease, HIV-course progress rapidly. Patient 6 developed severe depression post-OLT and did not tolerate the HAART therapy, which has to be ceased 62 days after transplantation. HIV- discase followed a progredient course under immunosuppression until patient's death 10 months post-OLT.

Cytomegalovirus infection (CMV) was diagnosed in 3 patients 4-8 weeks after OLT, and was successfully treated. No other opportunistic infections associated with HIV were noted.

\section{Clinical course of HBV and HCV}

Patients with $\mathrm{HBV}$ infection received standard prophylaxis with anti-HBs hyperimmunglobulin, beginning in the anhepatic phase during the OLT. These two patients received additionally lamivudine as part of their HAART therapy. In one of these patients (patient 1) came to a HBV recurrence under these measures, resulting to a progressive HBV-associated cholestatic hepatitis with secondary graft failure and paticnts death 34 months post-OIT.

Six patients suffered from chronic HCV co-infection. Shortly after OLT, in all of these patients HCV replication reached a similar level to $\mathrm{HCV}$ replication before OLT and took an accelerated cholestatic course in five of these patients. Liver biopsies were performed in all patients to rule out organ rejection or other causes of hepatitis.

Patient 2 has been relisted to OLT due to a progressive $\mathrm{HCV}$-associated cholestatic hepatitis with secondary graft failure.

In patient 4, portal fibrosis was diagnosed 18 months post-OLT. 31 months after OLT the paticnt died due to secondary graft failure following the toxic liver damage associated with the combination of chemotherapy against Hodgkin disease and chronic HCV progressive disease.

Patient 6 developed a severe form of progressive cholestatic hepatitis and died 10 months post-OLT due to secondary graft failure.

Patient 7 developed a progressive septal fibrosis within 19 months post-OLT. A combination treatment with pegylated interferon and ribavirin was initiated 3.5 months post-OLT. Under this therapeutic regimen the patient shows virological treatment responses with improvement of transaminases and $\mathrm{HCV}$ replication. Despite of progredient fibrosis his graft function remains normal 58 months post-OLT.

In patient 8 , clearance of HCV with interferon/ribavirin therapy was attempted before transplantation. Although the efficacy of this approach was poor ( $\mathrm{HC}$ virus genotype $1 \mathrm{~b}$ ), the patient remains 21 months post-OLT without HCV reinfection. In this HIV-positive patient an incidental-HCC was found in his liver explant. His HAART regimen included lamivudine, lopinavir, ritonavir and stavudine. Prior to OLT the CD4 T-cell count was 323 cells $/ \mu$ l and the HIV-viral load $<50$ copies $/ \mathrm{ml}$. Alfa-fetoprotein levels were within the normal range. Preoperative staging was negative for tumor or metastases. The patient showed a stable CD4 T-cell count and undetectable HIV-load under continuation of his pretransplant HAART. Histology showed two small $(0.7$ and $1.7 \mathrm{~cm})$ moderately differentiated HCCs with no vascular invasion. Follow-up studies revealed no evidence of tumor recurrence. The patient remains in very good general condition and has stable HIV disease on HAART, 21 months posttransplantation.

\section{Discussion}

Worldwide, an estimated 40 million persons are currently infected with HIV. Two to 4 million are chronically infected with HBV and 4 to 5 million have chronic HCV. Globally, HIV infection is mostly transmitted via heterosexual contacts, but intravenous drug use or homosexual contacts contribute to HIV epidemiology. Liver-related diseases among $\mathrm{HIV}$-infected patients are caused by HBV and HCV co-infections, hepatotoxic medication, alcohol, drugs, malignancies, metabolic 
and immunologic mechanisms, and non-HIV-related diseases [3]. Chronic infection with HIV and viral hepatitis $B$ and $C$ account for substantial morbidity and mortality worldwide. The need for liver transplantation in HIV-infected individuals is significant and is likely to grow with ongoing improvements in HIV management and the aging of the HIV-infected population. Recognition that introduction of HAAR'T has turned HIV into a chronic condition has been a gradual process in the transplantation community. Modern combination of antiretroviral therapy completely suppresses HIV-1 replication in plasma which results in restoration of cellular immune function, clinical improvement, and a dramatic decrease of mortality from AIDS [5-14].

However, the experience to date suggests that the use of standard immunosuppressive agents in patients with well-controlled HIV infection does not increase their susceptibility to opportunistic infections or malignant conditions. In these patients HIV load remains suppressed, CD4 T-cell counts remain stable, and opportunistic infections do not seem to increase considerably. However, rates of acute organ rejections are increased in these patients [7] having an effect on graft survival.

Until recently, HIV-positive patients were almost universally considered to be an absolute contraindication to transplantation. Early reports of OLT in HIVinfected individuals showed poor results. Pittsburgh was the first center to report its experience with $25 \mathrm{pa}$ tients [15]. Failure in the early 1990 s was due to poorer patient selection, lack of potent immunosuppression and availability of good antiviral agents. Multiple studies have reported promising outcomes at 1-, 3-, and 5 years after OLT in patients treated with HAART [6-7, 16-17].

In this study, we describe our experience and the clinical outcomes of 8 HIV-infected patients who undergone OLT for ESLD. Although a trend toward poorer overall survival with the actuarial 1-, 3-, and 5 year survival rate post-OLT of $63 \%, 31 \%$, and $31 \%$ respectively, three out of eight patients are alive 145 , 58 and 21 months after OLT. Five patients died 1, 3, 10,31 and 34 months posttransplant respectively as a result of severe septic conditions after early postoperative complications such as recurrent thrombosis of the hepatic artery, biliary leakage with abscess formation, situations causing mainly graft failure. In conjunction to our observations, these data suggest that HIV-infected population is particularly prone to infection as a cause of mortality after OLT despite good control of the HIV disease. The difference in mortality duc to infectious causes in our cohort suggests that, with a larger sample size, the difference in cumulative survival rates may reach statistical significance. Nevertheless, a mildly reduced cumulative survival for the HIV-infected population should not preclude OLT, as long as survival after OLT is significantly superior to that achieved without OLT in this population. [7, 16]

Acute cellular rejection was observed in $25 \%$ ( 2 of 8) of the HIV-infected patients. This is not different from current reports in the literature in which incidences of rejection range from $25 \%$ to $70 \%$. [7, 11 , 16, 18-19] All of the rejection episodes were easily treated with the protocols as previously described.
The prevalence of chronic HBV infection is between $6-17 \%$ among $H I V$-infected persons living in HBV endemic areas, and $4-17 \%$ among persons living in Europe or the USA depending on sexual or injection drug use behavior. The prevalence of HCV co-infection ranges from $1-5 \%$ in persons who acquired HIV infection by heterosexual or homosexual contacts to $70-95 \%$ in current or former injection drug users and transfused hemophiliac patients [3-4, 18, 20-21].

HBV does not seem to enhance HIV progression or affect antiretroviral treatment response, but increases liver-related mortality in co-infected persons. HBV-associated morbidity however, is reduced because of the use of nucleoside and nucleotide reverse-transcriptase inhibitors to treat HIV infection. Recent advances in the field include the use of tenofovir and emtricitabin as more effective antiviral treatment for HBV; tenofovir and emtricitabin are characterized by an acceptable tolerance and represent the modern antiviral therapy for patients with HIV and concomitant HBV infection. These substances also suppress HBV replication as long as treatment continues. HBV recurrence rates have fallen dramatically with an attending increase in both short-term and long-term survival [3-4, 7].

In our HIV-population patients with HBV infection received standard prophylaxis with i.v anti-HBs hyperimmunglobulin. They receive additionally lamivudine, tenofovir and emtricitabin as part of the HAART therapy. In one of these patients (patient 1) came to a HBV recurrence under these measures, as a consequence of lamivudine resistance, resulting to a progressive HBVassociated cholestatic hepatitis with secondary graft failure and patient's death 34 months post-OLT.

Concerns regarding HBV recurrence as a consequence of lamivudine resistance should be alleviated by emerging new therapies such as adenofovir, tenofovir, cmtricitabin and recently raltegravir $[2,4]$.

Co-infection with HIV and HCV is a major concern in liver transplant recipients, both in terms of treatment options and long-term effects on progression of liver disease $[4,8,22]$. In general, the management of co-morbidities and their increased risk is crucial in the treatment of these patients.

Recurrent hepatitis $\mathrm{C}$ infection remains a serious problem in HIV-negative patients. Because the degree of immunosuppression is a key factor on the activity of recurrent $\mathrm{HCV}$ infection, there has been concern that HIV-infected recipients may be at particular risk of experiencing aggressive HCV reinfection [10].

In our HIV-infected patient cohort, six patients suffered from chronic HCV co-infection. Shortly after OLT, in all of these patients HCV replication reached a similar level to HCV replication before OLT, and took an accelerated cholestatic course in five of these patients. Liver biopsies were performed in all patients to rule out organ rejection or other causes of hepatitis. However, it is possible that HAART-induced hepatotoxicity may have contributed to graft dysfunction in $\mathrm{HCV}$ coinfected patients. It is possible that inadequate HIV treatment and therefore immunosuppression related to HIV may have led to more aggressive recurrence of $\mathrm{HCV}$ infection. However, any effect on outcome is likely to reflect efficacy of the combination and not an effect of an individual drug. 
Each patient received individualized regimen based on known response and resistance patterns and preference of the physician. The need of HAART individualization has been acknowledged by others [2]. Pharmacological interactions between calcineurin inhibitors and protease inhibitor-containing HAART regimens have been documented. When considering the specific antiretroviral regimen, potential drug interactions must be taken into account. Protease inhibitors (PI) are a part of most HAART regimen. It is well known that PIs inhibit CYP3A, a component of the cytochrom $\mathrm{P} 450$, which results in markedly prolonged half-lives of the calcineurin inhibitors and sirolimus [7]. HIV patients may therefore be more prone to develop toxicity while on these medications, requiring lower doses.

On the other hand, when the decision to initiate $\mathrm{HCV}$ therapy is made, the HAART protocol must be considered. There are no specific interactions between the interferons and HAART. In contrary, several interactions between HAART and ribavirin are to be expected $[2,7]$.

Over 142 OLTs in HIV-positive patients, 26 cases of HIV-infected patients with concomitant viral hepatitis due to $\mathrm{HCV}(\mathrm{n}=20), \mathrm{HBV}(\mathrm{n}=5)$ or both ( $\mathrm{n}$ $=1$ ), and HCC are reported in the literature [8, 23-24]. In one patient in our series (patient 8), an incidentalHCC has been found in his liver explant. His HAART regimen included lamivudine, lopinavir, ritonavir and stavudine. Prior to OLT the CD4 T-cell count was $323 \mathrm{cells} / \mu \mathrm{l}$ and the HIV-viral load $<50 \mathrm{copies} / \mathrm{ml}$. The patient showed a stable CD4 T-cell count and undetectable HIV-load under continuation of his pretransplant HAART. Histology showed two small $(0.7$ and $1.7 \mathrm{~cm}$ ) moderately differentiated HCCs with no vascular invasion. Follow-up studies revealed no evidence of tumor recurrence. The patient remains in very good general condition and has stable HIV disease on HAART, 21 months posttransplantation.

However, development of HCC, especially in HBV and HCV-related liver cirthosis is another major indication for OLT. The published results of OLT in HIV-infected patients with HBV-and HCV-related HCCs using the Milan-criteria are very encouraging since recurrence was not observed. As HAART has turned HIV-infection into a chronic condition, transplant centers should accept to evaluate HIV-positive - $\mathrm{HBV} / \mathrm{HCV}$ co-infected patients, for both medical and ethical reasons. 'The presence of HCC represents an additional reason to transplant these patients, given that tumor characteristics are within the accepted criteria [8, 23-24].

Morbidity due to chronic infection with chronic-hepatitis-B (HBV) and HCV viruses has become a leading cause of death in HIV-infected patients with synchronous chronic viral hepatitis. Since the introduction of HAART 1996, the course of HIV-infection has changed dramatically. Therefore, HIV-positive patients are at greater risk of dying from complications of ESLD rather than HIV complications. The survival rate of HIV-positive patients with decompensated cirrhosis is much lower than that of HIV-negative patients; approximately $50 \%$ at 1 year follow-up. High mortality rates among coinfected patients with ESLD waiting for liver transplantation have also been report- ed in obscrvational studies [2, 23]. Not only because of psychosocial reasons but also due to historically poorer outcomes prior to HAART, OLT in the presence of HIV infection has been considered as contraindicated. Several serics have demonstrated comparable graft and patient-survival after OLT between HIV-negative recipients and HIV patients with ESLD due to chronic viral hepatitis and have shown the effectiveness of OLT as a therapeutic option in HIV-patients affected by ESLD [5-7] while OLT is the only therapeutic option for patients with ESDL, and HIV infection represent not a contraindication for liver transplantation [2-4].

Guidelines and reviews of OIT in HIV-infected individuals have recently been published. Current practice targets those with a low HIV viral load with limited or treated opportunistic infections and a CD4 Tcell count $>200 / \mathrm{ml}$ or $>100 / \mathrm{ml}$ in the presence of portal hypertension $[2,16-17,25]$.

OLT in the HIV context requires a multidisciplinary approach and is quite complex and challenging. ESDL. is an increasingly frequent clinical scenario in this setting. Early diagnosis of ESDL complications is particularly important and should be actively monitored and treated. OLT is a life-prolonging procedure in this population, and is quite safe in patients with $\mathrm{HBV}$ coinfection. However, HCV recurrent infection can affect both graft and patient survival in the medium and long-term. Larger prospective studies must be carried out in order to clarify further the specific problems of HIV-positive recipients and optimize the clinical care of thesc patients.

\section{REFERENCES}

1. Sotiropoulos GC, Lang $\mathrm{H}$, Nadalin $\mathrm{S}$, et al. Liver transplantation for hepatocellular carcinoma: University Hospital Essen experience and metaanalysis of prognostic factors. J Am Coll Surg. 2007; 205: 661-675.

2. Miro JM, Torre-Cisnero J, Moreno A, et al. ESIDA/ GESITRASEIMC, PNS and ONT Consensus Document on solid organ transplant (SOT) in HIV-infected patients in Spain Enferm Infecc Microbiol Clin 2005; 23: 353-362.

3. Samuel D, Weber R, Stock P, Duclos-Vallee JC, Terrault N. Are HIV-infected patients candidates for liver transplantation? J Hepatol 2008; 48:697-707.

4. Norris S, Taylor C, Muiesan P, et al. Outcomes of liver transplantation in HIV-infected individuals: The impact of HCV and HBV infection. Liver Transpl 2004; 10: 1271-1278.

5. De Vera ME, Dvorchik I, Tom K, et al. Survival of liver transplant patients coinfected by recurrent Hepatitis C. Am J Transp 2006; 6: 2983-2993.

6. Neff GW, Bonham A, Tzakis A, et al. Orthotopic liver transplantation in patients with Human Immunodeficiency Virus and end-stage liver disease. Liver Transpl 2003; 9: 239-247.

7. Schreibmann I, Gaynor JJ, Jayaweera D, et al. Outcomes after orthotopic liver transplantation in $15 \mathrm{HIV}$-infected patients. Transplantation 2007; 84: 697-705.

8. Fung J, Eghtesad B, Patel-Tom K, de Vera ME, Chapman $\mathrm{H}$, Ragni M. Liver transplantation in patients with HIV infection. Liver Transpl 2004; 10: S.39-53.

9. Radecke K, Frühauf NR, Miller M, et al. Outcome after orthotopic liver transplantation in five HIV-infected patients with virus hepatitis -induced cirrhosis. Iiver Int 2005; 25: 101-108. 
10. Vogel M, Voigt E, Schaefer N, et al. Orthotopic liver transplantation in Human Immunodeficiency Virus (HIV) -positive patients: Outcome of 7 patients from the Bonn Cohort. Jiver Transpl 2005; 11: 1515-1521.

11. Eisenbach C, Merle U, Stremmel W, Encke J. Liver transplantation in HIV positive patients. Clin Transplant 2009; 23: S68-74

12. Roland ME, Stock PG. Liver transplantation in five HIVinfected recipients. SeminLiver Dis 2006; 26: 273-284.

13. Terrault NA, Carter JT, Carlson I, Roland ME, Stock PG. Outcome of Patients with Hepatitis B virus and Human Immunodeficiency Virus infections referred for liver transplantation. Liver Transpl 2006; 12: 801-807.

14. Venarecci G, Ettorre GM, Antonini M, et al. Liver transplantation in HIV-positive patients. Transplant Proc 2007; 39: 1936-1938.

15. Tzakis AG, Cooper MH, Dummer JS, Ragni M, Ward JW, Starzl TE. Transplantation in HIV (+) patients. Transplantation 1990; 49: 354-358.

16. Neff GW, Scherman KE, Eghtesad B, Fung J. Current status of liver transplantation in HIV-infected patients. Aliment Pharmacol Ther 2004; 20: 993-1000.

17. Duclos-Vallee JC, Feray C, Sebagh M, et al. Survival and recurrence of hepatitis $\mathrm{C}$ after liver transplantation in patients coinfected with human immunodeficiency virus and hepatitis $C$ virus. Hepatology 2008; 47: 407-417.

18. Rafecas A, Rufi G, Figueras J, et al. Liver transplantation without steroid induction in HIV-infected patients. Liver Transpl 2004; 10: 1320-1323.

19. Singal AK, Anand BS. Management of hepatitis $C$ virus infection in HIV/HCV co-infected patients: Clinical review. World J Gastroenterol 2009; 15: 3713-3724.

20. Adeyemi OM. Hepatitis C in HIV-positive patients Treatment and liver disease outcomes. J Clin Gastroenterol 2007; 41: 75-87.
21. Castells L, Escartin A, Bilbao I, Ien O, Allende H, Vargas V, et al. Liver transplantation in HIV - HCV coinfected patients: A case-control study. Transplantation 2007; 83: 354-358.

22. Prachalias $\Lambda A$, Pozniak $A$, Taylor $C$, et al. Liver transplantation in adults coinfected with HIV. Transplantation 2001; 72: 1684-1688.

23. Di Benedetto F, De Ruvo N, Berretta M, et al. Hepatocellular carcinoma in HIV patients treated by liver transplantation. Eur J Surg Oncol 2008; 34: 422-427.

24. Vernadakis S, Mathe Z, Kaiser GM, et al. Liver transplantation in cirrhotic patients with hepatocellular carcinoma and concomitant HIV infection : two more reasons to accept or to deny ? Transplantation 2010; 90: 97-98.

25. O'Grady J, Taylor C, Brook G. Guidelines for liver transplantation in patients with HIV infection. HIV Med 2005; 6: S149-153.

Received: November 14, 2010 / Accepted: January 6, 2011

Address for correspondence:

Prof. Dr. Georgios C. Sotiropoulos, FACS, FEBS

Department of General, Visceral and Transplantation Surgery University Hospital Essen

Hufelandstrasse 55

45122 Essen, Germany

Tel.: $\quad+49-201-72384002$

Fax: +49-201-7231113

E-mail: georgios.sotiropoulos@uni-due.de 